УДК 334.012 .6

\title{
ПРЕДМЕТНАЯ ОБЛАСТЬ ИССЛЕДОВАНИЯ В СОВРЕМЕННОЙ ТЕОРИИ ПРЕДПРИНИМАТЕЛЬСТВА
}

\author{
О.В. ТЕЛЕГИНА \\ старший преподаватель кафедры «Экономическая теория» \\ Гомельского государственного технического университета \\ имени П.О. Сухого
}

Аннотация

В статье рассмотрена предметная область исследования феномена малого предпринимательства в работах современных американских и европейских исследователей - лауреатов Международной премии за вклад в исследования предпринимательства и малого бизнеса.

Ключевые слова: мальй бизнес, теория предпринимательства, инновации, социальные сети, государственная экономическая политика.

\section{Abstract}

The article considers the subject of research of a phenomenon of small business in the works of contemporary American and European researchers laureates of the International award for contribution to the study of entrepreneurship and small business. Marked brief conclusions of the research.

Key words: small business, the theory of entrepreneurship, innovation, social networks, government economic policy.

\section{ВВЕДЕНИЕ}

Теорию предпринимательства как отдельную исследовательскую область стали признавать лишь в 1990-е годы. Однако до сих пор нет единого мнения о том, что является предметом исследования в теории предпринимательства. В данной статье предпринята попытка выделить предметную область исследования в современной теории предпринимательства, основываясь на трудах признанных исследователей - лауреатов Международной премии за вклад в исследования предпринимательства и малого бизнеса за период с 1996 по 2010 гг. Данная премия присуждается ежегодно, начиная с 1996 г., Шведским фондом исследования в области малого бизнеса (FSF) и Шведским агентством экономического и регионального развития (NUTEK). В 2009 г. ее статус повысился до Всемирной премии за исследования в области предпринимательства. 
Вследствие своей многогранности явление предпринимательства привлекает исследователей из таких общественных наук как экономикс (Д. Бёрч, У. Баумоль, И. Кирцнер, Д. Стори, 3. Акс, Д. Одретч, Дж. Беккатини), менеджмент (А. Купер, Я. Макмиллан, Б. Йоханниссон), социология (П. Рейнольдс, Г. Олдрич). Именно междисциплинарный подход помогает более полно оценить данное явление. Результаты исследований этих ученых весьма убедительны вследствие собранного богатого эмпирического материала. Самым масштабным международным исследовательским проектом в области предпринимательства считается созданный в 1997 г. консорциум «Глобальный мониторинг предпринимательства» (Global Entrepreneurship Monitor, GEM), включающий на сегодняшний день более 100 стран-участниц.

\section{РЕЗУЛЬТАТЫ И ИХ ОБСУЖДЕНИЕ}

Нефтяные кризисы 1970-х годов вызвали пересмотр роли малых фирм в экономическом развитии. Крупные компании все чаще демонстрировали негибкость и медлительность в приспособлении к новому состоянию рынка. Возросший интерес к малым фирмам был обусловлен [2]: 1) коренным изменением в мировой экономике, связанным с усилением глобальной конкуренции, что привело к росту степени неопределенности, а также большей фрагментации рынка, 2) изменением в характеристиках технического прогресса, дающих крупным фирмам меньше преимуществ. Новые тенденции были отражены в многочисленных научных работах по вопросам предпринимательства и роли малого бизнеса.

\section{Роль малого бизнеса в социально-экономическом развитии}

Оценка значимости малого бизнеса в социально-экономическом развитии чаще рассматривается с точки зрения его вклада в создание новых рабочих мест как фактора социальной стабильности и генерирование инноваций как источника экономического роста.

- создание новых рабочих мест

Исследованию роли малого бизнеса в создании рабочих мест посвящена пионерская и по праву считающаяся революционной работа Дэвида Бёрча «Процесс создания рабочих мест» (1979) [1, с. 16]. Он утверждал, что малые фирмы являются двигателем экономики - создают больше рабочих мест, чем крупные компании, растут быстрее, демонстрируют большую приспособляемость и гибкость. Результаты лонгитюдных исследований с 1969 по 1976 годы показали, что 60\% рабочих мест в экономике США в этот период создано малыми фирмами с численностью работников до 20 человек и возрастом до четырех лет. Данные выводы вызвали шквал критики, преимущественно в части методологии оценки. Компромиссом в наметившейся дискуссии стали 
совместные исследования оппонентов по данному вопросу Д. Бёрча и Дж. Медофа, в результате которых был сделан следующий вывод: роль малого бизнеса в создании рабочих мест очень сильно варьируется во времени и пространстве, наибольший вклад в их создание вносят «газели»- малочисленные, но быстрорастущие компании.

Попытки повторить исследования Д. Бёрча в данной области предприняли Дэвид Стори и Стивен Джонсон («Создание рабочих мест и изменения на рынке труда», 1987) [1, с. 80]. Результаты, к которым пришли исследователи: масштаб созданных рабочих мест не столь значителен, как показал Д. Бёрч; доля новых и растущих малых фирм, создающих значительное число рабочих мест, невелика; нет простого и универсального объяснения относительного роста числа малых фирм в экономике. Главный вывод Стори и Джонсона перенес акцент c количественной значимости малых фирм на их качественную составляющую: относительно небольшое число определенных малых фирм становится драйвером роста в экономике.

Подобные выводы подтверждаются результатами эмпирических исследований, проведенных в рамках «Глобального мониторинга предпринимательства» (GEM) в 34 странах с 1998 по 2003 гг. [1, с. 425]: большинство стартапов не создают растущих компаний. Чаще предприниматели рассматривают свой бизнес как альтернативу занятости по найму, а доходы от предпринимательской деятельности как заменитель заработной платы. В результате такие компании скорее являются формой самозанятости, не обладающей высоким потенциалом роста.

\section{- создание инноваций}

Еще один дискуссионный вопрос касается вклада малого бизнеса в технологические инновации. Арнольд Купер в статье «НИОКР более эффективны в малых компаниях» (1964) делает вывод о том, что затраты времени и средств на разработку продукта у крупных фирм выше. Существует три фактора, которые могут объяснить преимущества малых фирм: средние способности технического персонала в малых фирмах выше (квалификация, креативность, способность видеть сущность задачи); интерес технического персонала к оценке стоимости осуществляемых проектов; менее затратная коммуникация и координация в малых фирмах [1, с. 36].

Сравнивая инновационную активность малых и крупных фирм, Золтан Акс совместно с Дэвидом Одретчем (1990) выявили различия в зависимости от отрасли. В одних отраслях (производство вычислительной техники) малые компании являются более инновационными, в других же (фармацевтика, авиация) значительная часть инноваций производится крупными компаниями. Крупные 
предприятия имеют явные преимущества в отраслях со значительной экономией от масштаба производства. 3. Акс и Д. Одретч обнаружили, что крупные фирмы, работающие в промышленности, производили не намного больше значимых инноваций, чем малые фирмы. Однако количество инноваций в расчете на одного работающего в малых фирмах было значительно выше, чем на крупных предприятиях. 3. Акс утверждает, что малые предприятия выходят на рынок не с целью копирования продукции крупных компаний. Они выступают агентами изменений, так как производят другой продукт, используя другие факторы и технологии производства, стремясь проявить инновационную активность [1, с. 163].

Уильям Баумоль в своих многочисленных трудах дает оценку роли предпринимательства в экономическом росте. Продолжая идею Й. Шумпетера о влиянии инноваций на экономическое развитие, Баумоль указывает на различие и взаимодополняемость инновационного вклада крупных и малых предпринимательских фирм [1, с. 215]. Исследования показали, что малые фирмы совершают чаще революционные прорывы, тогда как непрерывный поток частичных усовершенствований создается крупными компаниями. На крупных предприятиях инновационная деятельность контролируется менеджерами, которые стремятся снизить риски и, как следствие, изменения в продуктах являются более умеренными. Однако будучи накопленными, малые улучшения создают гораздо больше возможностей, чем первоначальное прорывное изобретение.

Йош Лернер, известный благодаря своим пионерским исследованиям в области венчурного капитала, указывает на более высокую отдачу у малых венчурных предприятий в виде инновационного результата от затрат на НИОКР в сравнении с крупными корпорациями. Кортам и Лернер в совместной работе (2000) приводят доказательство того, что венчурный капитал повышает инновационный потенциал новых предпринимательских фирм. Используя данные о затратах на НИОКР в качестве переменной для оценки технологических возможностей, они пришли к выводу, что на один доллар венчурного капитала приходится в среднем в 3-4 раза более высокая отдача в виде инновационного результата, чем на один доллар традиционных корпоративных вложений в НИОКР [1, с. 485].

Ранние исследования в области предпринимательства чаще акцентировали внимание на личностных характеристиках предпринимателя и поиске факторов успеха фирм. Кто чаще становится предпринимателем? Как от типа личности зависит дальнейшее развитие фирмы? Что способствует развитию и выживаемости малого предприятия? 


\section{Типология предпринимательских личностей}

Типология многообразия личностей предпринимателей способствует пониманию предпринимательства как явления, дает основания для предсказания их поведения и результатов. Одним из первых масштабных исследований типологии владельцев бизнеса стало исследование А. Купера и У. Данкельберга [1, с. 43]. В своей работе (1982) они описали три типа владельцев бизнеса, которые различались по происхождению и предыдущему опыту: ориентированные на рост, ориентированные на независимость, ориентированные на мастерство.

Женское предпринимательство как объект для исследования стало интересовать в начале 1980-х годов. Предметным полем были личностные качества и мотивация, а также отличительные признаки от типичных мужчин-предпринимателей. К 1990-м годам женское предпринимательство прочно закрепилось в программе исследований. В 1999 г. в США сформировался коллективный исследовательский проект «Диана», основанный женщинами и ставший впоследствии международным [1, c. 363]. Исследование сфокусировано на определенной группе женщинпредпринимательниц, которые стремятся к росту своего бизнеса. Особенностью данного проекта стало рассмотрение женского предпринимательства как составной части предпринимательства в целом, без акцента на его подобие или отличие от мужского предпринимательства.

Оценка факторов успеха (выживаемости, роста)

Оценивая предпосылки к успеху нового частного бизнеса, А. Купер на основе лонгитюдных исследований (1994) выделяет фaкторы выюивания и факторы интенсивного развития малых фирм. Под интенсивным развитием понимался ежегодный рост минимум на $50 \%$ и увеличение сотрудников более, чем на 2 человека [1, с. 32]. Факторы, повлиявшие как на выживание, так и на рост - образование, схожесть нового предприятия с предыдущим, на котором прежде работал предприниматель, больший стартовый капитал. Факторы, способствующие только выживанию, - опыт родителей в ведении бизнеса, наличие консультантов. С успешным интенсивным развитием (но не выживанием) оказались связанными пол (мужчины более стремительно развивали свой бизнес) и наличие партнеров. Таким образом, стартовый человеческий и финансовый капитал влияет на дальнейшее развитие создаваемого частного малого бизнеса.

\section{Процесс формирования новых фирм}

Большое количество исследований посвящено оценке потенциальных предпринимателей. Что толкает предпринимателя на открытие собственного бизнеса? При каких условиях стартапы появляются чаще? В каких странах предпринимательский потенциал выше? 
А. Купер, исследуя малые фирмы из Кремниевой долины США (1971, 1985, 1990), определил, что в создании большинства новых фирм участвовали не приезжие, а местные жители, которые использовали существующие связи, основанные на прежних профессиональных знакомствах, знания местного рынка и поставщиков. Предприниматель открывает бизнес в той же отрасли, где прежде работал по найму. Организации, из которых работники увольняются для открытия своего бизнеса, А. Купер называет предприятиями-«инкубаторами» [1, с. 41]. В качестве мотивации, которая заставила потенциальных предпринимателей оттуда уйти и начать самостоятельный бизнес, - недовольство своей работой. Выявлена зависимость от размера фирмы: чем меньше фирма, тем больше частота возникновения на ее базе новых частных фирм. Причина: в небольших организациях сотрудники обладают более обширной подготовкой, т.е. малые фирмы являются хорошим образовательным полигоном для потенциальных предпринимателей.

Понятие «предпринимательское инкубирование» встречается также в работах Й.Лернера с соавторами (2005). Результаты исследований предпринимательских фирм, основанных на венчурном капитале, показали, что эти фирмы выступают «сеятелями» новых, также основанных на вен-чурном капитале, предприятий, производящих высокую добавленную стоимость [1, с. 486]. Предпринимательский опыт и сети выступают теми каналами, которые генерируют целый каскад новых стартапов.

Пионерская работа Д. Бёрча о создании рабочих мест, вышедшая в США в 1979 г. и вызвавшая ряд дискуссий, побудила американского социолога Пола Д. Рейнольдса заняться исследованием процесса формирования новых фирм в региональном разрезе. В 1994 г. исследование с участием П. Рейнольдса было проведено в шести европейских странах (Франции, Германии, Италии, Северной Ирландии, Швеции, Великобритании) и США. Результаты продемонстрировали одинаковые факторы, оказывающие влияние на формирование новых фирм - это показатели роста спроса, урбанизации, безработицы, благосостояния региона и доля малого бизнеса в экономике региона.

П. Рейнольдс, принимавший активное участие в разработке методологии и понятийного аппарата исследовательской программы «Глобальный мониторинг предпринимательства» $(G E M)$, в качестве основных результатов первых исследований приводит выявленное различие в причинах, побудивших предпринимателей создать свой бизнес $[1$, c. 251]. Для развивающихся стран главной причиной создания бизнеса является «вынужденное» предпринимательство, связанное с безработицей или отсутствием адекватных возможностей занятости, тогда как в развитых странах - «добровольное» предпринимательство, связанное 
с желанием извлечь выгоду из новых бизнес-возможностей. Степень вовлеченности в предпринимательство внутри страны со временем меняется, но очень медленно. Исследование «нарождающихся» предпринимателей показало, что в богатых странах наблюдается сокращение числа потенциальных предпринимателей и соответственно стартапов, а в бедных - высокий уровень стартовой предпринимательской активности, не приводящая однако к возникновению значимых фирм.

Скотт Шейн, опираясь на результаты исследований $G E M$, объясняет тот факт, что в развитых странах число стартапов снижается, тогда как в развивающихся, наоборот, - растет. С ростом благосостояния страны растет уровень заработной платы, рассматриваемый как альтернативные издержки ведения собственного бизнеса, что заставляет все большее количество людей искать работу по найму. Как результат - уровень активности создания новых фирм в богатых странах снижается.

С оценкой зарождающегося и уже функционирующего развивающегося малого бизнеса связаны многочисленные исследования институциональной среды: социальных сетей, кластеров, промышленных районов.

\section{Предпринимательская среда}

- социальные сети

Важность социальных сетей для предпринимательской деятельности тема, к которой в числе первых проявил интерес социолог Говард Олдрич. Выгодой от налаживания связей и установления деловых контактов может стать доверие и предсказуемость как результат установления долговременных отношений. Противоположной ситуацией является рыночный механизм, основанный на единоразовых трансакциях, обладающих оппортунистическим потенциалом. Подтверждение значимости влияния социальных сетей на создание бизнеса и его прибыльность отмечено в результатах панельных лонгитюдных исследований потенциальных и активных предпринимателей Северной Каролины (США), проведенное Г. Олдричем с соавторами в 1986 г. [1, с. 151]. Выявлено, что социальные сети позволяют начинающим предпринимателям получить доступ к ресурсам и возможностям. Результаты второго панельного исследования с участием Г. Олдрича $(1993,1995)$ однако не обнаружили значимого влияния сетевой деятельности (измеряемой как размер личной сети предпринимателя и времени, затрачиваемого на развитие и поддержание бизнес-контактов) на уже действующий бизнес и его выживание. Международные сопоставления личных сетей для пяти стран: Италии, Японии, Северной Ирландии, Швеции и США (1998) показали схожесть их по структуре. Наиболее распространены личные сети, основанные на дружбе и длительном знакомстве. Это объясняется тем, что в условиях 
неопределенности предприниматели стремятся получить социальную поддержку, необходимую для развития компании.

Бенгт Йоханниссон, шведский исследователь, указывает на двоякое использование предпринимателями локальных сетей: реактивным и проактивным способами. Взаимодействия в сетях являются как спонтанными, так и просчитанными. Решения принимаются исходя из ситуации, причем значимую роль при принятии решений играют эмоциональные аспекты - аффект и интуиция. В этом отличие взглядов Йоханниссона от англосаксонских исследователей (Олдрича, Зиммера), которые рассматривают сети как дополнительный ресурс и указывают на рациональное экономическое взаимодействие в рамках сетей.

\section{- промыиленные районы (регионы)}

Исследование промышленных районов зародилось в Италии. Джакомо Бекаттини, основываясь на монографии Альфреда Маршалла «Экономика промышленности» (1879, совместно с Мэри П. Маршалл), рассматривает в качестве альтернативы крупным, вертикально интегрированным, промышленным предприятиям с полным производственным циклом сеть мелких фабрик, выполняющих определенные стадии производственного процесса и сосредоточенных в одном регионе.

Работа Майкла Пиора и Чарльза Сейбла «Второй индустриальный раздел» (1984) привлекла внимание мировой общественности к явлению промышленных районов [1, с. 212]. В ней узкоспециализированные малые фирмы, обеспечивающие высокую гибкость посредством сетевого сотрудничества, представлены как конкурирующие стратегии производству, основанному на принципах массового производства.

\section{Государственные программы поддержки малого бизнеса}

Рост числа малых предприятий в экономике развитых стран в 1970-1980-е гг. и обусловленные этим явлением научные исследования, оценивающие значимость частного малого предпринимательства для развития экономики, привлекли внимание правительства. Экономическая политика государственной поддержки сектора малого и среднего бизнеса стала неотъемлемой частью экономической политики развитых стран. Ученые, выделяя экономическую политику в качестве объекта для исследования, пытаются обосновать ее необходимость, оценить эффективность ее проведения, а также сформировать рекомендации по ее улучшению.

Оценка регулирующего воздействия государственной политики по поддержке сектора малых предприятий, предпринятая Д. Стори (1994), начинается с конкретизации целей [1, с. 54]. По мнению Д. Стори, невозможно оценить эффективность проводимой политики, зная только задекларированные меры поддержки малого бизнеса. Правительства же не всегда четко определяют цели проводимой политики. Далее следуют 
мониторинг (наблюдение и фиксирование индикаторов) и оценивание, предполагающее сравнение позиции фирмы-бенефециара и фирмы, не включенной в действие политики. К сожалению, как считает Д. Стори, чаще результаты политики поддержки предпринимательства рассматривают лишь по итогам мониторинга, не проводя оценивания.

Эффективность проводимой экономической политики по поддержке предпринимательства ставит под сомнение С. Шейн. В силу того, что не все создаваемые фирмы способны генерировать значительное количество рабочих мест и значительную добавленную стоимость, по мнению Шейна, политикам следует поддерживать не всех потенциальных предпринимателей, «размазывая масло тонким слоем», а малочисленную группу зарождающихся фирм с потенциально высокими показателями эффективности. Таковыми являются фирмы, которые стремятся внедрять инновации.

Необходимость государственного вмешательства с целью поддержки предпринимательства рассматривается и в работах Й. Лернера. Он приводит три довода за вмешательство государства [1, с. 462]: ключевым источником экономического роста являются технологические инновации; в качестве основного фактора развития инноваций выступают предпринимательство и венчурные инвестиции; государство при определенных условиях может эффективно содействовать развитию предпринимательства и венчурного инвестирования. Далеко не все государственные программы поддержки предпринимательства в мировой практике можно рассматривать как успешные. Однако имеются примеры, подтверждающие, что это все-таки возможно: программа Small Business Investment Company (SBIC) в США, созданная в 1992 году израильским правительством компания по привлечению венчурного капитала Yozma Venture Capital Ltd, образованный в 1999 году Новозеландский венчурный инвестиционный фонд New Zealand Venture Investment Fund (NZVIF).

\section{ВЫВОДЫ}

Предпринимательство как область исследований имеет свои истоки в различных дисциплинах и эволюционировала в течение нескольких десятилетий. Предметная область исследований в современной теории предпринимательства включает следующие направления: влияние малого бизнеса на экономический рост и благосостояние, процесс зарождения фирм, инновационное предпринимательство с участием венчурного капитала, социальные сети, кластеры фирм, экономическая политика поддержки малого предпринимательства.

Оценка роли малого бизнеса в социально-экономическом развитии до сих пор является дискуссионной. Малые фирмы далеко не всегда 
генерируют большее количество рабочих мест по сравнению с крупными предприятиями. Однако результаты исследований показывают, что среди малых фирм выделяется малочисленная группа быстрорастущих инновационных предприятий («газелей»), которые и являются создателями значительного числа рабочих мест, источником экономического роста и зачастую выступают «инкубатором» для таких же инновационных малых предприятий с высоким потенциалом роста. Мотивация нарождающихся предпринимателей связана, как правило, с «вынужденным» или «добровольным» предпринимательством. Последнее имеет больший потенциал роста, т.к. основано на открывшихся бизнес-возможностях и на стремлении повысить свой уровень жизни, тогда как первое выступает альтернативой получаемой ранее заработной платы. Ресурсную и психологическую поддержку предприниматели получают через социальные сети.

Исследовательский акцент на стартующий инновационный малый бизнес с высоким потенциалом роста, который является драйвером экономического развития, позволяет сформулировать принципы для экономической политики. Оказывать поддержку следует не всем стартапам, дабы не распылять безрезультатно средства налогоплательщиков, а тем малым фирмам, которые способны к росту.

\section{ЛИТЕРАТУРА}

1. Современные классики теории предпринимательства. Лауреаты Международной премии за вклад в исследования предпринимательства и малого бизнеса (1996-2010) / Пер. с англ. под науч. ред. А.Ю. Чепуренко. М.: Изд. дом Высшей школы экономики, 2013. - 526 с.

2. Carlsson B. et al. The evolving domain of entrepreneurship research //Small Business Economics. 2013. Vol. 41. P. 913-930.

Статья поступила в редакиию 9 августа 2016 года. 